PROCEEDINGS, INDONESIAN PETROLEUM ASSOCIATION

Thirtieth Annual Convention \& Exhibition, August 2005

\title{
ORIGIN AND PETROPHYSICAL LOG RESPONSE OF OVERPRESSURES IN THE BARAM DELTA PROVINCE, BRUNEI
}

\author{
Mark R. P. Tingay* \\ Richard R. Hillis** \\ Richard E. Swarbrick*** \\ Chris K. Morley****
}

\begin{abstract}
The 'window' of safe mud weights between pore pressure and fracture pressure is narrower in overpressured sediments than in normally pressured sediments. This 'window' also controls the maximum buoyancy pressure, and hence the maximum height of hydrocarbon columns. Therefore, accurate pore pressure prediction is of critical importance for hydrocarbon exploration. Accurate pore pressure prediction is especially important in the rapidly depositing $(3000 \mathrm{~m} / \mathrm{Ma})$ Tertiary Baram Delta Province where all economic fields exhibit overpressures, often of high magnitude and with narrow transition zones. A database of pore pressure information was compiled for 157 wells in 61 fields throughout Brunei. Overpressures are observed in 54 fields both in the inner shelf deltaic sequences and the underlying pro-delta shales. Porosity-vertical effective stress plots from 31 fields reveal that overpressures are primarily generated by disequilibrium compaction in the pro-delta shales, but have been vertically transferred into the inner shelf deltaic sequences. Sediments overpressured by disequilibrium compaction exhibit different physical properties to those overpressured by vertical transfer and hence, different pore pressure prediction strategies need to be applied in the prodelta shales and inner shelf deltaic sequences. Sonic and density log data detects overpressures generated by disequilibrium compaction and pore pressures are accurately predicted using an Eaton exponent of 3.0. Sonic log data detects vertically transferred overpressures, even in the absence of a porosity anomaly, and pore pressures are reasonably predicted using an Eaton exponent of 6.5 .
\end{abstract}

\footnotetext{
* World Stress Map Project, University Karlsruhe

** University of Adelaide

*** Durham University

**** PTT Exploration and Production, Bangkok.
}

\section{INTRODUCTION}

Pore pressure prediction is essential to ensure safe drilling operations in overpressured regions and is a fundamental input into well design, in particular for selecting casing points (Law and Spencer, 1998; Sayers et al., 2002). Furthermore, pore pressure prediction provides valuable data for reservoir planning and reserves estimation (Mouchet and Mitchell, 1989; Law and Spencer, 1998). Accurate pore pressure prediction is particularly critical in the Baram Delta province of Brunei (Sandal, 1996; Tingay, 2003). The Baram Delta province contains numerous overpressure-related structures such as shale diapirs and mud volcanoes, and overpressures are observed in almost every field (Sandal, 1996; Morley et al., 1998; van Rensbergen et al., 1999). Furthermore, overpressures in Brunei commonly exhibit magnitudes approaching the lithostatic gradient and have rapid onsets across faults and thin shales, resulting in numerous blowouts and kicks (Sandal, 1996; Tingay, 2003).

Pore pressure prediction involves quantifying pore pressure from rock property variations (Bell, 2002; Sayers et al., 2002). However, in order to accurately predict pore pressure it is necessary to first understand the mechanisms of overpressure generation and the ways in which different overpressure generating mechanisms affect rock properties (Swarbrick, 2000). Hence, this paper examines the origin of overpressure in the Baram Delta province, the effect of overpressure on sonic and density logs, and tests a sonic log-based pore pressure prediction strategy for Brunei.

\section{GEOLOGICAL SUMMARY OF THE BARAM DELTA PROVINCE}

The Baram Delta province is comprised of three Tertiary deltaic systems that were deposited adjacent to the NW Borneo active margin (Figure 1; 
Sandal, 1996). Continental collision between salients of the South China Sea and the continental core of Borneo began in the Mid-Miocene and has continued in pulses into the Quaternary, causing widespread inversion and uplift, particularly in the deltaic hinterland (Morley et al., 2003; Tingay et al., 2003). The rapid uplift and equatorial setting of the Crocker-Rajang range has resulted in the deposition of largely fine-grained sediments at very high deposition rates $(3000 \mathrm{~m} / \mathrm{Ma}$; Sandal, 1996). Numerous overpressured shale structures (shale diapirs, dykes and laccoliths and mud volcanoes) are observed throughout the region in association with the basal pro-delta shales (Morley et al., 1998; van Rensbergen et al., 1999). Fault inversion associated with the active margin compression has also resulted in large volumes of fluid being transferred to shallower units (Grauls and Belaix, 1994).

\section{OVERPRESSURE DISTRIBUTION}

A database of petroleum industry pore pressure information (repeat formation tests, drill stem tests, kicks and mud weights) from 157 wells in 61 fields was compiled as part of this study and revealed the distribution and characteristics of overpressures in Brunei.

(i) Overpressures are observed in most wells and fields in Brunei (101 out of 157 wells and 54 out of 61 fields examined) and occur throughout the onshore and offshore regions of the Baram Delta province (Figure 2).

(ii) Overpressures commonly occur in or near the pro-delta shales (Sandal, 1996; Tingay, 2003).

(iii) The onset of overpressure in the outer shelf is approximately coincident with the top of the pro-delta shales (Figure 2).

(iv) Shallow onset overpressures in the inner shelf are in regions that have been uplifted and/or are near shale diapirs (Figure 2; Sandal, 1996; Tingay, 2003).

(v) Overpressures in the inner shelf are highly compartmentalised by faults and shale intervals (Figure 3).

\section{ORIGIN OF OVERPRESSURE}

Overpressures are usually classified as being generated by two distinct and separate mechanisms: disequilibrium compaction and fluid expansion (Swarbrick and Osborne, 1998). Disequilibrium compaction overpressures result from the rapid loading (burial) of an effectively sealed pore volume (Swarbrick and Osborne, 1998). Fluid expansion overpressures refer to numerous mechanisms that cause an increase in the amount of pore fluid within a confined pore space (Mouchet and Mitchell, 1989). Herein, we used porosityvertical effective stress plots to distinguish between overpressures generated by disequilibrium compaction and fluid expansion (Figure 4 and 5; Bowers, 1994).

Porosity-vertical effective stress plots were compiled using 575 overpressured and 825 normally pressured wireline formation interval tests (WFITs or Repeat Formation Tests) from 90 wells in 31 fields and reveal that disequilibrium compaction overpressures occur in the outer shelf, whereas fluid expansion overpressures are located in the inner shelf (Figure 5). Furthermore, this remarkably clear boundary between different overpressure types is approximately coincident with the change in characteristics of the top of overpressure and the outer limit of Pliocene inversion (Figure 2). This geographical separation is interpreted to be the result of the petroleum data being sourced from separate stratigraphic units. Petroleum exploration in the inner shelf is almost completely within the thick deltaic sequence. However, the deltaic units are very thin in the outer shelf and exploration has focused on turbidite reservoirs within the pro-delta shales (Sandal, 1996). Therefore, the observed stratigraphic relationship suggests that:

- overpressures in the pro-delta shales are generated by disequilibrium compaction, and;

- overpressures in the overlying deltaic sequences are generated by fluid expansion.

There are several hypothesised fluid expansion mechanisms (e.g. clay diagenesis and aquathermal expansion), but only the maturation of kerogen into gas is believed to be able to cause high magnitude overpressure (Swarbrick and Osborne, 1998). However, no significant source rock material occurs in the deltaic sequences and hence, kerogen-to-gas maturation cannot have resulted in the generation of overpressures in the inner shelf (Sandal, 1996; Tingay, 2003). The coincidence of the outer limit of Pliocene uplift and the border between fluid 
expansion and disequilibrium compaction overpressures suggests an alternative 'fluid expansion' mechanism for overpressure generation in the deltaic sequences - the 'vertical transfer' of overpressured fluids from the pro-delta shales into the deltaic sequences through faults and fractures (Tingay, 2003). Overpressuring by vertical transfer has been hypothesised, but rarely demonstrated, and only ever at small scales (Grauls and Belaix, 1994; Lee and Deming, 2002). However, the geological separation of overpressure mechanisms in Brunei and the high degree of compartmentalisation of overpressures in the inner shelf suggests the first evidence for regional, high magnitude overpressure development by vertical transfer.

\section{SONIC AND DENSITY LOG RESPONSE TO OVERPRESSURE}

The ultimate aim of all pore pressure prediction strategies is the accurate and reliable prediction of pore pressures from seismic processing velocities (Bell, 2002). Disequilibrium compaction overpressures are the most commonly observed overpressures in sedimentary basins (Swarbrick and Osborne, 1998). Disequilibrium compaction overpressures are associated with abnormally large porosities (undercompaction), which cause a detectable decrease in the overpressured sediment's sonic velocity (Mouchet and Mitchell, 1989). Thus, successful pore pressure prediction (both pre-drill and from logging while drilling methods) is commonly undertaken in sequences with disequilibrium compaction overpressure (Bell, 2002; Sayers et al., 2002). However, fluid expansion overpressures may be generated after maximum burial and are not associated with a significant porosity anomaly (Hansen, 1996; Hermanrud et al., 1998). Hence, the biggest drilling risk and most difficult challenge for pore pressure prediction in Brunei, and indeed worldwide, is the detection and quantification of the high magnitude and compartmentalised overpressures in the inner shelf caused by vertical transfer.

The response of sonic and density logging data to overpressure was examined in 24 wells across Brunei by means of calculated shale porosities. Sonic and density log data were each used to estimate shale porosity, and calibrated such that the sonic and density data would provide the same porosity estimate in normally pressured sequences (Hansen, 1996; Tingay, 2003). The key results of this analysis were that:
- both the sonic and density log data exhibited a large response to overpressures generated by disequilibrium compaction (Figure 6), and;

- the sonic log data exhibited a small response in overpressures generated by vertical transfer but the density log showed no response (Figure 7).

The different responses exhibited by the sonic and density $\log$ are believed to be the result of the logging tool characteristics. The density logging tool uses gamma ray scattering to estimate the bulk rock density, and thus, provides an estimate of the true bulk rock porosity. Therefore, the density log 'sees' the abnormally high porosity in sediments that are overpressured by disequilibrium compaction, but there is no porosity anomaly that can be detected by the density log in sediments overpressured by vertical transfer. However, the sonic logging tool measures the travel time of compressional waves through the rock, and thus measures the 'easiest' (fastest) path between the acoustic transmitter and receiver. It is postulated that vertically transferred overpressures (even in the absence of a physical porosity anomaly) reduce the effective stress across grain contacts and thereby reduce the measured sonic velocity (Hermanrud et al., 1998). Hence, the sonic log to overpressure is interpreted respond to both the undercompaction associated with disequilibrium compaction overpressure and to small textural changes directly associated with the overpressure itself (in both disequilibrium compaction and vertical transfer overpressures).

\section{PORE PRESSURE PREDICTION}

The sonic log response to fluid expansion/vertical transfer overpressures, albeit minor, is extremely significant. It indicates that fluid expansion/vertical transfer overpressures are theoretically detectable and quantifiable from sonic velocity data in Brunei. The Eaton (1972) method was used to test pore pressure prediction from sonic log data in 13 outer shelf and 6 inner shelf wells. The Eaton (1972) method estimates pore pressure from the ratio of acoustic travel time in normally compacted sediment to the observed acoustic travel time:

$$
P_{p}=\sigma_{v^{-}}\left(\sigma_{v}-P_{h}\right)\left(\Delta t_{n o r m} / \Delta t\right)^{x}
$$

where $\mathrm{x}$ is an exponent, $\mathrm{P}_{\mathrm{h}}$ is hydrostatic pore pressure, $\Delta t_{\text {norm }}$ is the acoustic travel time from the normal compaction trend at the depth of investigation and $\Delta \mathrm{t}$ is the observed acoustic travel 
time from the sonic log. The Eaton (1972) method is used herein because the exponent can be easily varied to calibrate the method to estimate overpressure generated by different mechanisms. An Eaton (1972) exponent of 3.0 is typically used in sediments where the overpressure has been generated by disequilibrium compaction (Mouchet and Mitchell, 1989). However, the sonic log response is smaller in sediments containing vertical transfer overpressures, and so a higher exponent needs to be used in order to amplify this response.

The exponents used herein were determined by averaging the exponents that would exactly predict the pore pressure measured from the 575 overpressured WFIT measurements used in the porosity-vertical effective stress analysis. An average Eaton (1972) exponent of 3.0 (with a standard deviation of 0.7 ) was determined from 113 overpressured WFITs in the outer shelf. The 462 overpressured WFITs in the inner shelf yield an average Eaton (1972) exponent of 6.5 (with a standard deviation of 2.5).

Pore pressure was successfully predicted using an Eaton (1972) exponent of 3.0 in the 13 outer shelf wells, where the overpressures are generated by disequilibrium compaction (Figure 8). Pore pressure prediction was not as accurate in the inner shelf wells where overpressure is generated by vertical transfer. However, a reasonable pore pressure prediction was obtained using the Eaton (1972) exponent of 6.5 (Figure 8).

\section{SUMMARY: A PORE PRESSURE PREDICTION STRATEGY FOR THE BARAM DELTA PROVINCE}

These results form the necessary foundation for a pore pressure prediction strategy from seismic processing velocities in the Baram Delta Province and can be applied directly to real-time loggingwhile-drilling pore pressure prediction. The key aspects of the pore pressure prediction strategy developed herein for the Baram Delta province are that:

- overpressures are widespread in the pro-delta shales and are caused by disequilibrium compaction;

- overpressures have been vertically transferred into the overlying deltaic sequences, resulting in a highly compartmentalized and dangerous overpressure distribution;
- pore pressures can be accurately predicted in the pro-delta shales (outer shelf) from sonic log data by using the Eaton (1972) method with an exponent of 3.0 , and;

- pore pressures in the inner shelf deltaic sequences are detectable on the sonic log and can be reasonably predicted by using the Eaton (1972) method with an exponent of 6.5.

\section{ACKNOWLEDGEMENTS}

The authors would like to thank Brunei Shell Petroleum, and Steve Drake and Dr. Abdul Razak Damit in particular, for providing the data for this study and for permission to publish these results.

\section{REFERENCES}

Bell, D.W., 2002, Velocity estimation for porepressure prediction. In Huffman, A.R. and Bowers, G.L., eds., Pressure Regimes in Sedimentary Basins and Their Prediction: AAPG Memoir 76, Tulsa, p. 177-215.

Bowers, G.L., 1994, Pore pressure estimation from velocity data: Accounting for overpressure mechanisms besides undercompaction: 1994 IADC/SPE Drilling Conference, p. 515-530.

Eaton, B.A., 1972, Graphical method predicts geopressures worldwide. World Oil, 182, 51-56.

Grauls, D.J., and Baleix, J.M., 1994, Role of overpressures and in situ stresses in fault-controlled hydrocarbon migration: a case study. Marine and Petroleum Geology, 11, 734-742.

Hansen, S., 1996, A compaction trend for Cretaceous and Tertiary shales on the Norwegian Shelf based on sonic transit times. Petroleum Geoscience, 2, 159-166.

Hermanrud, C., Wensaas, L., Teige, G.M.G., Vik, E., Bolas, H.M.N., and Hansen, S., 1998, Shale porosities from well logs on Haltenbanken (offshore mid-Norway) show no influence of overpressuring. In Law, B.E., Ulmishek, G.F., and Slavin, V.I., eds., Abnormal pressures in hydrocarbon environments: AAPG Memoir 70, Tulsa, p. 65-85.

Law, B.E., and Spencer, C.W., 1998, Abnormal pressure in hydrocarbon environments. In Law, B.E., Ulmishek, G.F., and Slavin, V.I., eds., 
Abnormal pressures in hydrocarbon environments: AAPG Memoir 70, Tulsa, p. 1-11.

Lee, Y., and Deming, D., 2002, Overpressures in the Anadarko basin, southwestern Oklahoma: static or dynamic?. AAPG Bulletin, 86, 145-160.

Morley, C.K., Crevello, P., and Ahmad, Z.H., 1998, Shale tectonics and deformation associated with active diapirism: the Jerudong Anticline, Brunei Darussalam. Journal of the Geological Society, London, 155, 475-490.

Morley, C.K., Back, S., Crevello, P., van Rensbergen, P., and Lambiase, J.J., 2003, Characteristics of repeated, detached, MiocenePliocene tectonic inversion events, in a large delta province on an active margin, Brunei Darussalam, Borneo. Journal of Structural Geology, 25, 1147 1169.

Mouchet, J.P., and Mitchell, A., 1989, Abnormal Pressures While Drilling: Elf Aquitaine Publication, Boussens, $255 \mathrm{p}$.

van Rensbergen, P., Morley, C.K., Ang, D.W., Hoan, T.Q., and Lam, N.T., 1999, Structural evolution of shale diapirs from reactive rise to mud volcanism: 3D seismic data from the Baram delta, offshore Brunei Darussalam. Journal of the Geological Society, London, 156, 633-650.
Sandal, S.T., 1996, The Geology and Hydrocarbon Resources of Negara Brunei Darussalam: Syabas Publication, Bandar Seri Begawan, 243 p.

Sayers, C.M., Johnson, G.M., and Denyer, G., 2002, Predrill pore-pressure prediction using seismic data. Geophysics, 67, 1286-1292.

Swarbrick, R.E., and Osborne, M.J., 1998, Mechanisms that generate abnormal pressures: an overview. In Law, B.E., Ulmishek, G.F., and Slavin, V.I., eds., Abnormal pressures in hydrocarbon environments: AAPG Memoir 70, Tulsa, p. 13-34.

Swarbrick, R.E., 2000, The challenge of porosity based pore pressure prediction: Proceedings of the Overpressure 2000 Workshop, p. 35-37.

Tingay, M.R.P., 2003, In situ stress and overpressures of Brunei Darussalam: University of Adelaide PhD Thesis, Adelaide, $271 \mathrm{p}$.

Tingay, M.R.P., Hillis, R.R., Morley, C.K., Swarbrick, R.E. and Okpere, E.C., 2003, Variation in vertical stress in the Baram Basin, Brunei: tectonic and geomechanical implications. Marine and Petroleum Geology, 20, 1201-1212. 


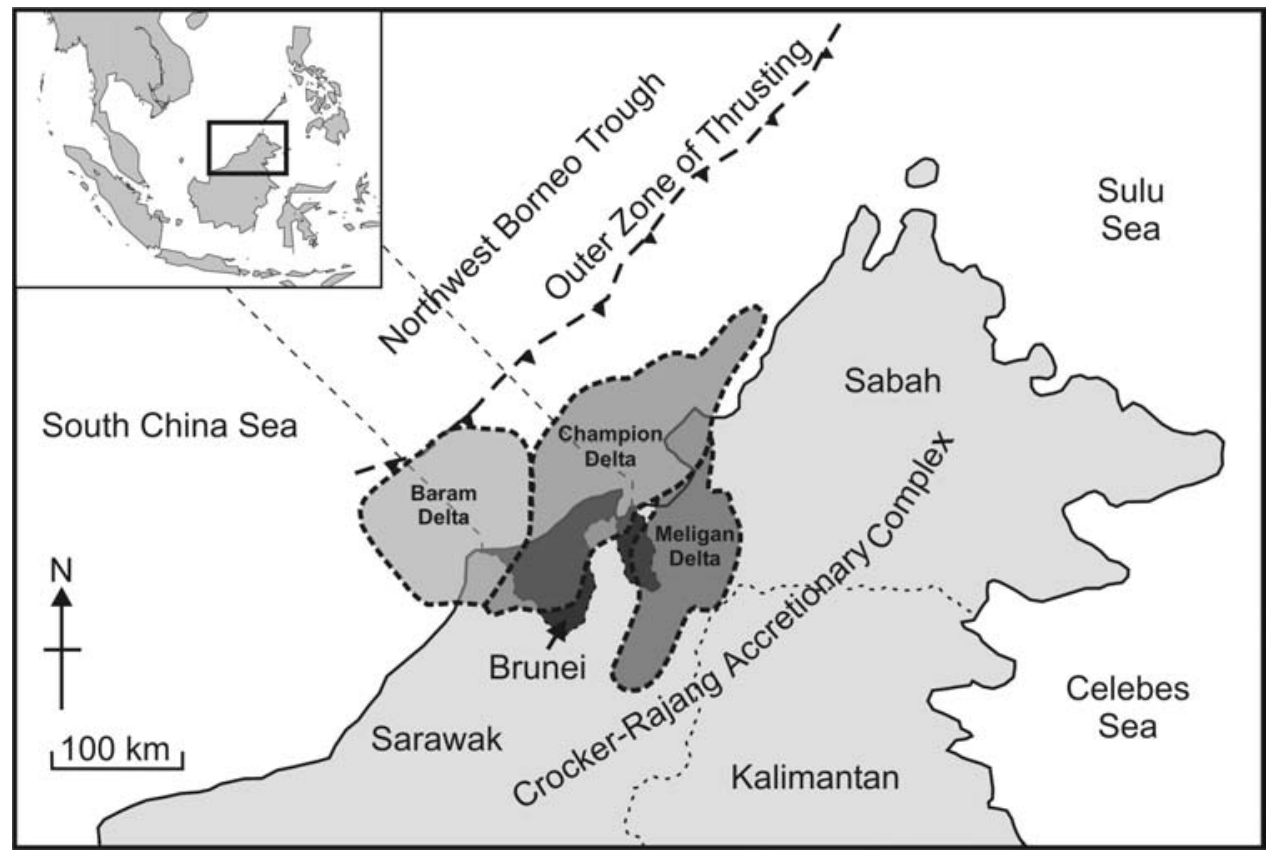

Figure 1 - Geological framework of the Baram Delta province including location of the three major Tertiary delta systems, the Crocker-Rajang accretionary complex and the NW Borneo active margin (expressed at present-day by the outer zone of thrusting and the NW Borneo trough). Adapted from Sandal (1996).

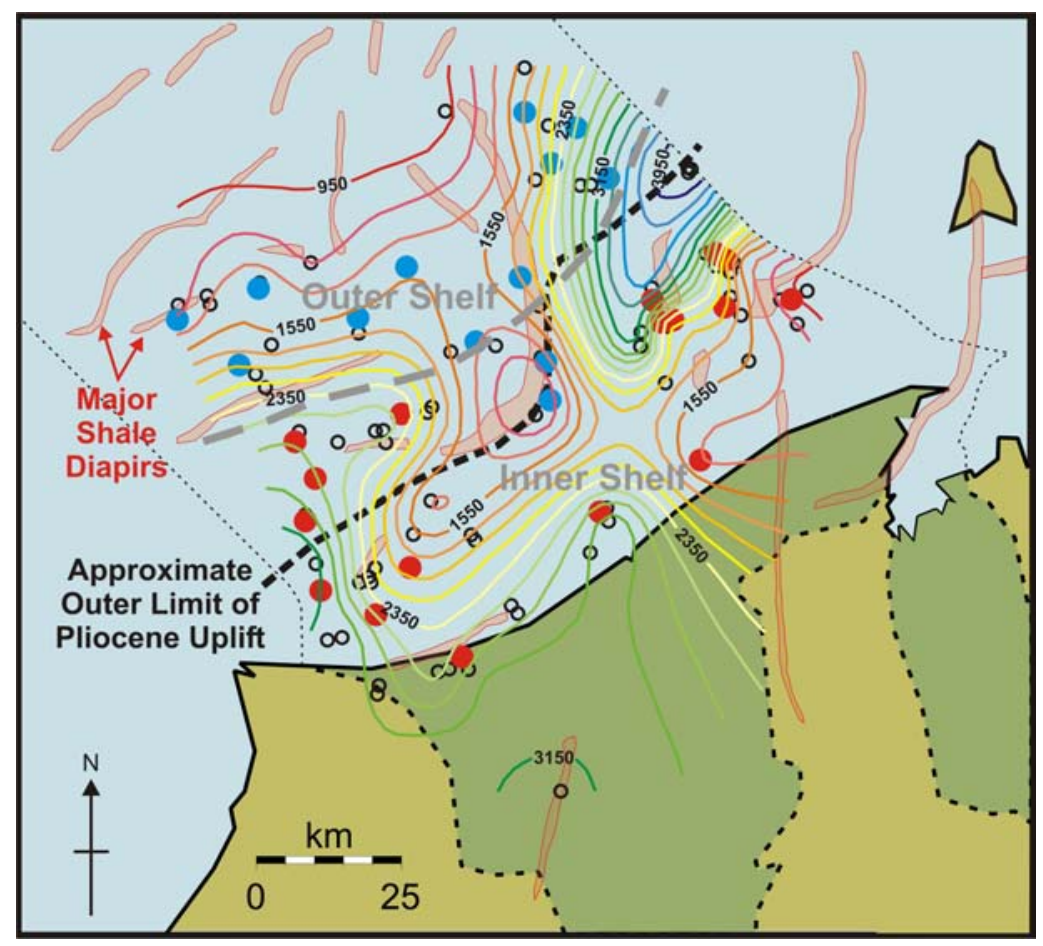

Figure 2 - Depth (in metres below seabed) to top of overpressure from 101 overpressured wells (black circles) and location of wells with disequilibrium compaction (blue dots) and vertical transfer overpressures (red dots). Contour interval is 200 metres. Onset of overpressure in the outer shelf is approximately co-incident with top of pro-delta shales. Overpressures in the inner shelf are commonly associated with shale diapirs and/or are in uplifted regions (outer limit of Pliocene uplift from Morley et al., 2003). Note the clear geographic separation between fields with disequilibrium compaction overpressures (outer shelf) and vertical transfer overpressures (inner shelf). 


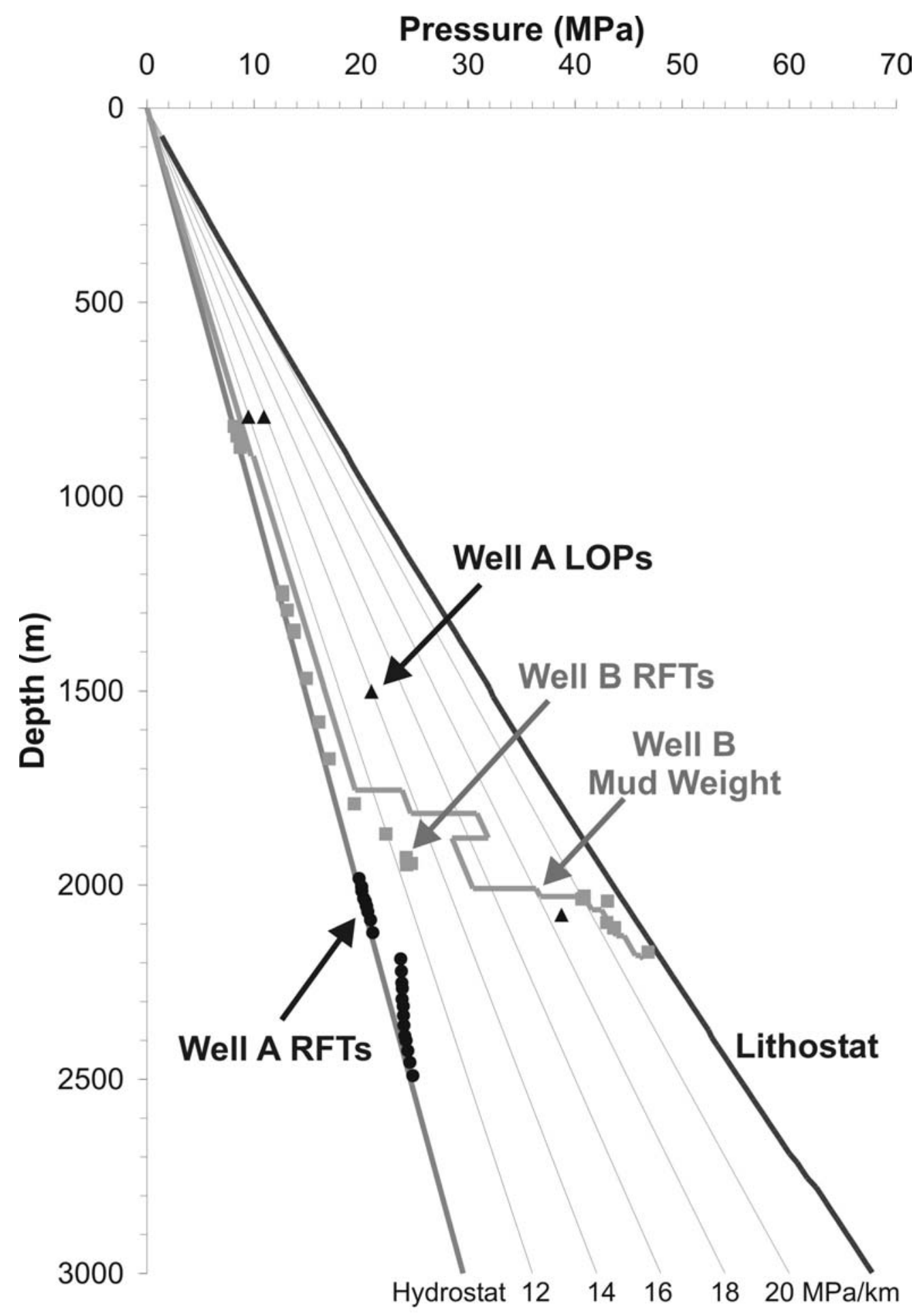

Figure 3 - Pressure-depth plot for inner shelf wells A (Black) and B (grey). Wells A and B are located $\approx 500$ $\mathrm{m}$ apart and are separated by a single fault (of $60 \mathrm{~m}$ throw). Pore pressure in Well B increases sharply by $20 \mathrm{MPa}$ at $\approx 2000 \mathrm{~m}$ depth (across a $12 \mathrm{~m}$ thick shale). However, Well A is normally pressured down to $2500 \mathrm{~m}$ depth, indicating strong fault compartmentalisation of overpressures. 
(a)

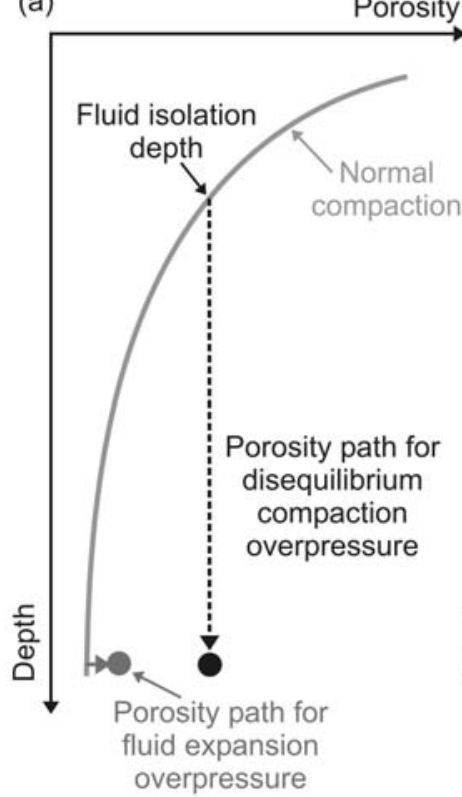

(b)

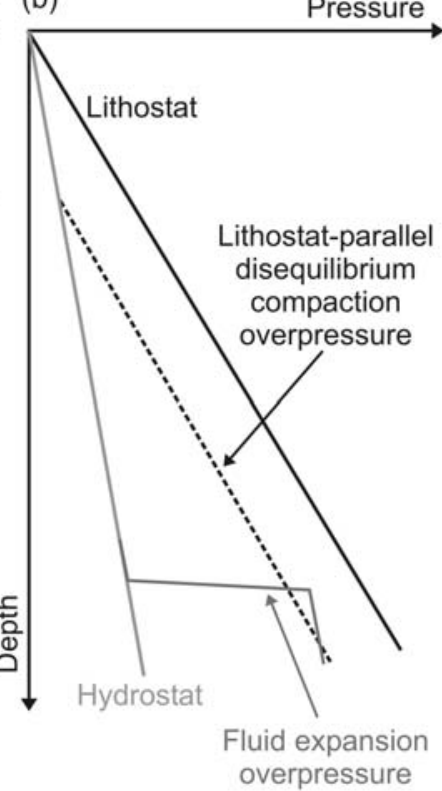

(c)

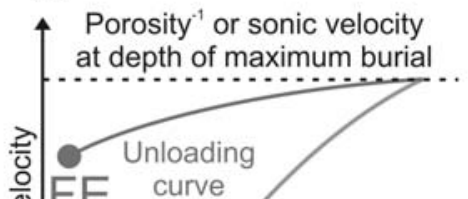

Figure 4 - (a) Schematic porosity-depth and (b) pressure-depth paths for overpressure generated by disequilibrium compaction and fluid expansion/vertical transfer. (c) Porosity-effective stress schematic of overpressured sediments where overpressure is generated by DC: disequilibrium compaction where sediments plot on the loading curve, and FE: fluid expansion/vertical transfer during which sediments follow an unloading curve (modified after Bowers, 1994).

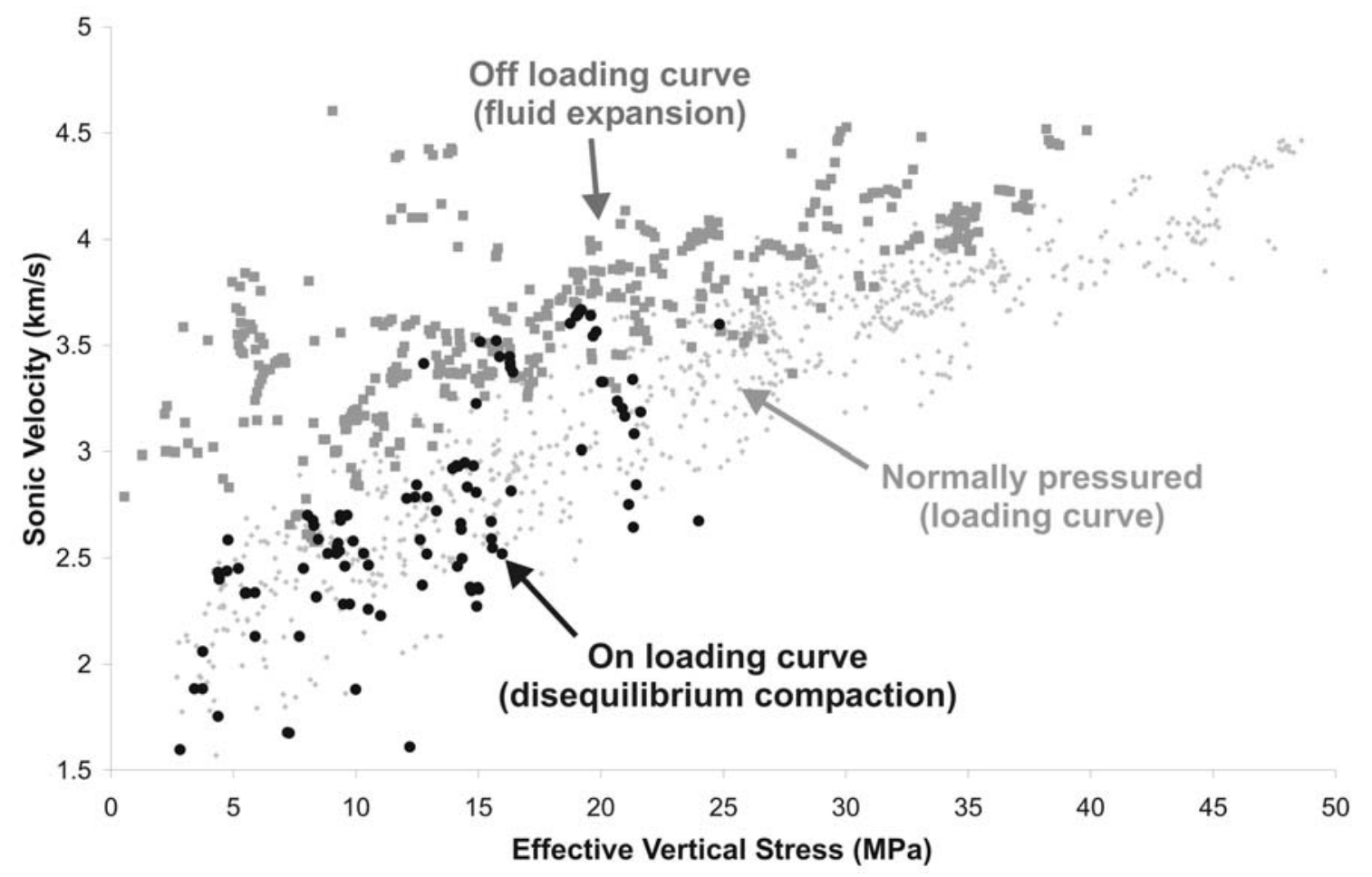

Figure 5 - Porosity (sonic velocity) - vertical effective stress plots for Brunei. Overpressured points from fields that lie predominantly 'on the loading curve' (black dots) indicating disequilibrium compaction and fields that predominately lie 'off the loading curve' (dark grey squares) indicating fluid expansion. Small light grey dots are normally pressured points that define the loading curve. 


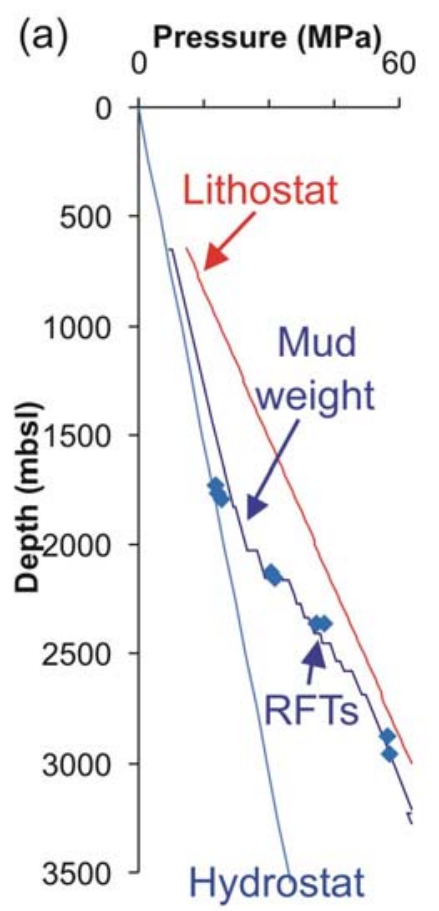

(b) $\underset{0}{\sigma v}$ Effective (MPa)
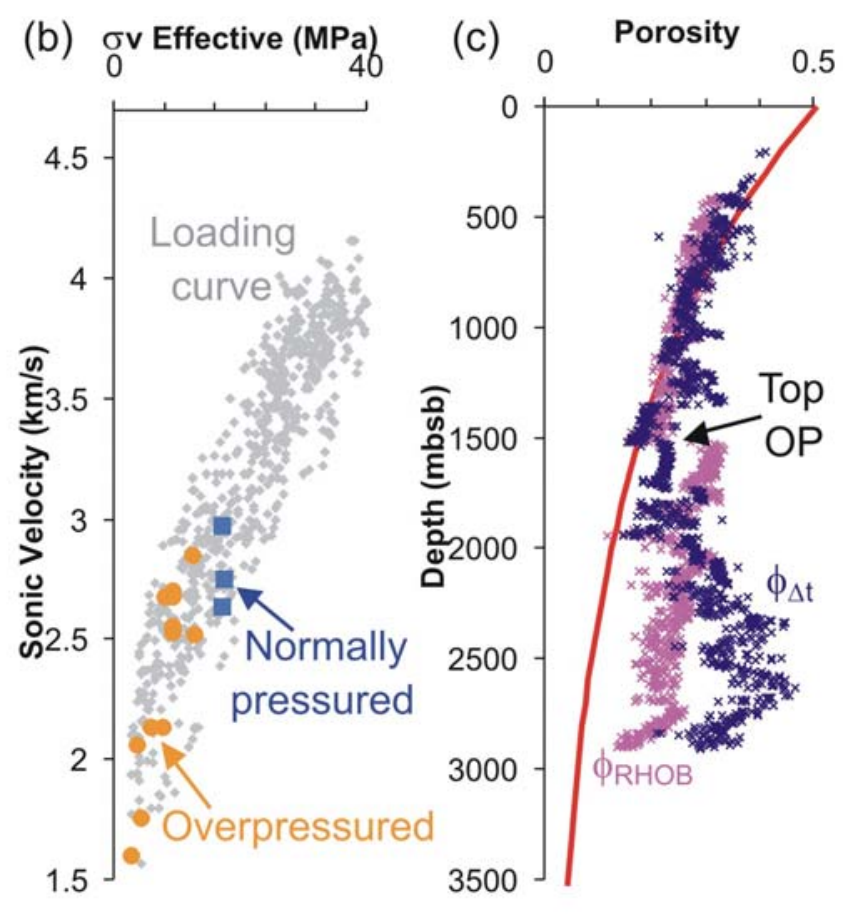

Figure 6 - Outer shelf Well X (a) Pressure-depth plot showing overpressures below $2000 \mathrm{~m}$ below sea level $(\approx 1500 \mathrm{~m}$ below seabed). (b) Sonic velocity-effective stress plot indicating overpressures generated by disequilibrium compaction. (c) Shale porosities estimated from sonic (blue) and density (pink) log data. Both sonic and density log data responds to the overpressure (abnormally high porosities).
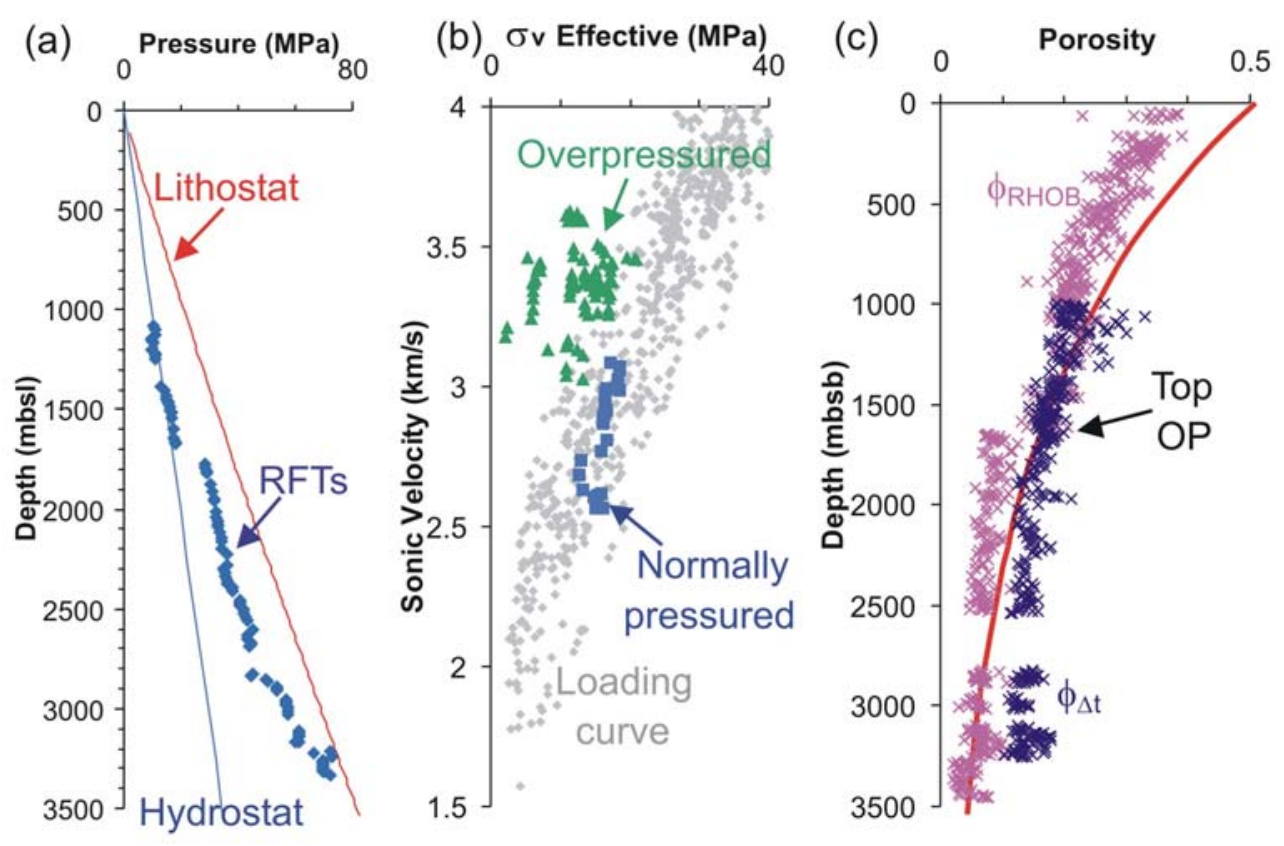

Figure 7 - Inner shelf Well Y (a) Pressure-depth plot showing sediments overpressured below 1650 mbsl (1600 mbsb). (b) Sonic velocity-effective stress plot indicates overpressures caused by vertical transfer. (c) Shale porosities estimated from sonic (blue) and density (pink) log data. The sonic $\log$ detects the overpressure (albeit with a minor response) but the density log shows no response. 

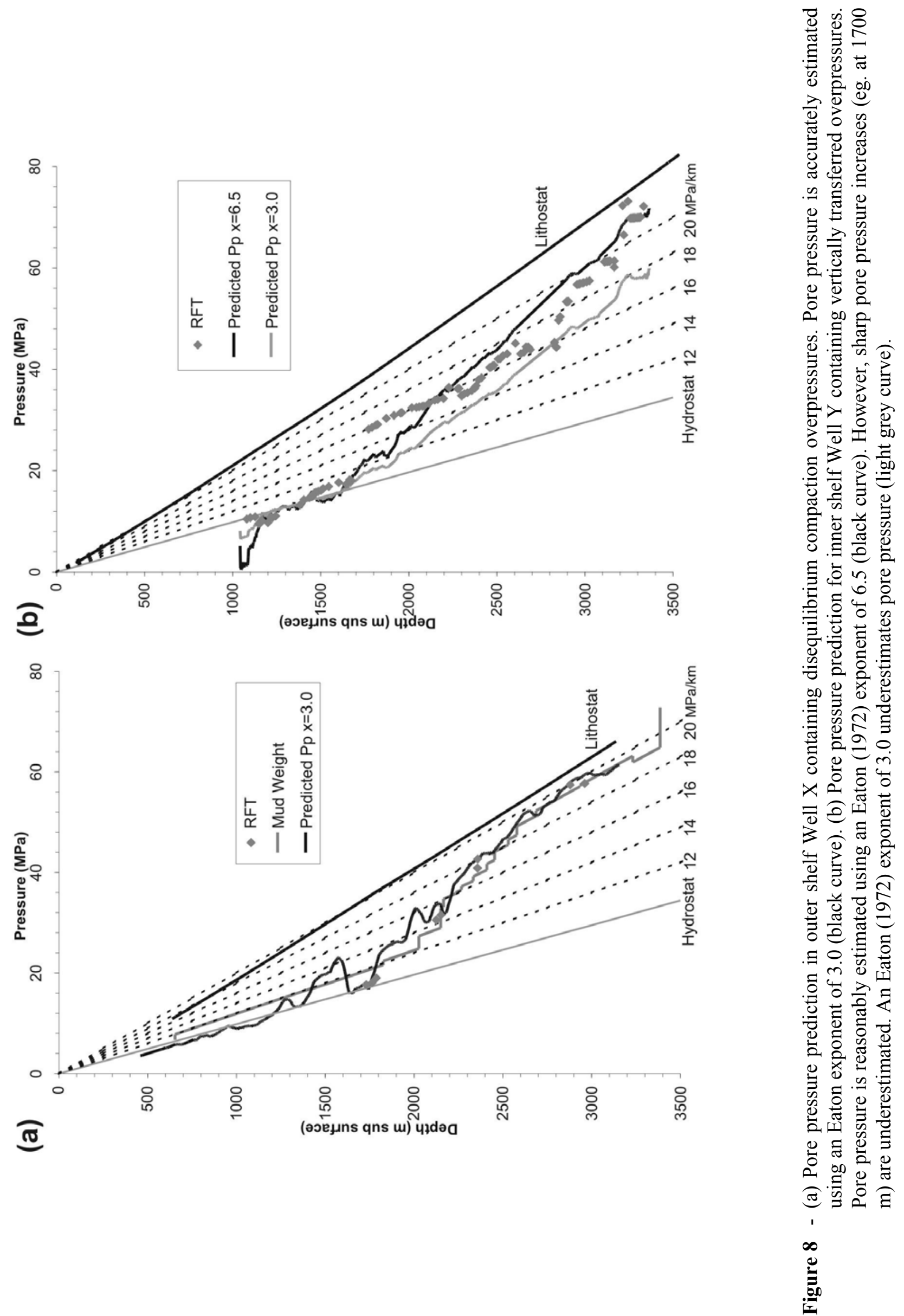